\title{
Consequences of concurrent Ascaridia galli and Escherichia coli infections in chickens
}

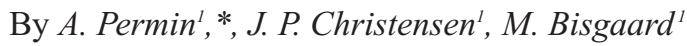 \\ ${ }^{1}$ Department of Veterinary Pathobiology, The Royal Veterinary and Agricultural University, \\ Stigbøjlen 4, 1870 Frederiksberg C., Copenhagen, Denmark.
}

\begin{abstract}
Permin A, Christensen JP, Bisgaard M. Consequences of concurrent Ascaridia galli and Escherichia coli infections in chickens. Acta vet. scand. 2006, 47, 43-53. - Three experiments were carried out to examine the consequences of concurrent infections with Ascaridia galli and Escherichia coli in chickens raised for table egg production. Characteristic pathological lesions including airsacculitis, peritonitis and/or polyserositis were seen in all groups infected with E. coli. Furthermore, a trend for increased mortality rates was observed in groups infected with both organisms which, however, could not be confirmed statistically. The mean worm burden was significantly lower in combined infection groups compared to groups infected only with $A$. galli. It was also shown that combined infections of $E$. coli and A. galli had an added significant negative impact on weight gain.
\end{abstract}

Ascaridia galli; E. coli; interactions; free-range layer chickens

\section{Introduction}

Ascaridia galli and Escherichia coli are both common causes of infections in confined as well as in free-range poultry productions systems (Dho-Moulin and Fairbrother, 1999; Permin et al. 1999).

Pathogenic E. coli may cause airsacculitis, salpingitis, peritonitis, polyserositis, septicemia and other extra-intestinal diseases in chickens, turkeys and other avian species. However, E. coli also constitutes part of the intestinal microflora of healthy birds and most of the diseases associated with $E$. coli are considered secondary to environmental and host predisposing factors (Dho-Moulin and Fairbrother 1999). Clinical isolates of avian E. coli commonly belong to certain serogroups, i.e. O1, $\mathrm{O} 2$ and $\mathrm{O} 78$, and to a restricted number of clones (White et al. 1993). Experimental infections have shown that the air-exchange regions of the lungs and the airsacs are important sites of entry of $E$. coli into the bloodstream of birds during the initial stages of infection and that resistance to phagocytosis may be an important mechanism in the development of the disease (Gross 1990). It has also been demonstrated that F1 fimbriae are expressed in the respiratory tract, whereas P fimbriae are expressed in the internal organs of infected chickens (Vidotto et al. 1990). Unambiguous virulence factors associated with $E$. coli infections in avian species, remain to be identified. Diagnosis of E. coli infections is based on the clinical picture, lesions and isolation of E. coli (Dho-Moulin and Fairbrother 1999).

A. galli may cause anorexia, weight loss, haemorrhages in the intestinal mucosa, obstruction

\footnotetext{
* Corresponding author. Tel: +45 35282748. Fax: +45 35283762. E-mail: ape@kvl.dk (A. Permin).
} 
of the intestinal lumen, altered hormone level and eventually death (Ackert 1931, Ikeme 1971, Roepstorff et al. 1999) in a wide range of avian species. The life cycle of $A$. galli is direct with a prepatent time of minimum 28 days under temperate climatic conditions (Permin et al. 1998). After ingestion of the infective egg, the egg hatches in the small intestine where the larva embeds in the mucosal layer of the duodenum for a varying period of 3- 56 days depending on age and immunity of the bird (Herd and McNaught 1975). After maturation of the worm, it migrates to the intestinal lumen where it lives from intestinal contents and occasionally from host blood. The mature worms copulate and might start producing eggs after 28 days. Diagnosis of $A$. galli is based on faecal isolation of parasite eggs or direct identification of adult worms in the intestine (Permin and Hansen 1998).

Few pathogen interaction studies have been carried out in poultry. Okulewicz and Zlotorzycka (1985) showed that $A$. galli exerted an inhibiting effect on the natural bacterial micro flora of the intestine of hens. The opposite situation, where the bacterial flora of the intestine inhibited the establishment of $A$. galli was demonstrated by Stefanski and Przyjakowski (1967). Chadfield et al. (2001) showed an interaction between the intestinal flora and $A$. galli, where the bacterium Salmonella enteriditis was incorporated into the eggs of $A$. galli. This finding, however, is in contrast to the finding of Baron et al. (1960), where the eggs of $A$. galli were found to be sterile. To the knowledge of the authors nobody has examined the interaction between E. coli and A. galli infections in chickens. Consequently this study has been designed to investigate the possible effect of two common concurrent infections; $A$. galli super imposed with $E$. coli and vice versa, on establishment of the respective infections, pathological lesions, mortality and impact on selected production parameters.

\section{Materials and methods}

Experimental animals

Female Lohman Brown chickens were used for all experiments. The chickens were purchased as one-day-old chicks and kept for one week in a confined parasite free environment until the experiment. The chickens were given a commercial feed containing $20 \%$ protein and water ad libitum. The chickens were kept in one flock until infection whereafter they were placed in separate houses.

\section{Infection material}

A clinical nalidixic_acid_resistant O78 E.coliisolate originating from broilers suffering from respiratory distress (difficulties in breathing) was grown overnight in an enrichment media (LB-broth) to reach the desired infection dose (Lee and Arp 1998). The number of bacteria pr. $\mathrm{ml}$ (cfu) was determined by spectophotometry and plate counts.

A. galli eggs were isolated from mature female worms obtained from layers and embryonated in $0.1 \mathrm{~N}$ sulphuric acid according to the method described by Permin et al. (1997b).

\section{Experimental design}

In total, three experiments were carried out. The first experiment was conducted to determine the route and dose of the $E$. coli having clinical impact without killing all chickens, a prerequisite for the following two trials. The infection dose and infection route of $A$. galli was set to be 500 embryonated eggs given as a single oral infection in all three experiments according to previous studies by Permin et al. (1997a). The last two experiments were designed as 2 x 2 cohort studies, i.e., groups with or without $A$. galli and E. coli infections including a control group (Thrusfield 1995). 
Determination of dose and infection route of $E$. coli

Fifty-two one-week-old chickens were purchased and were kept for seven days to acclimatise in the new environment. The chickens were divided into 9 groups of which 7 groups each consisted of 6 animals and 2 groups of each 5 animals. The animals were infected as given in Table 1. The primary infection with $A$. galli or E. coli took place on day 0 of the experiment. The secondary infection was carried out seven days after the first infection. All chickens were killed on day 14 and subjected to post mortem examinations (Permin and Hansen 1998).

\section{Final experiments}

Based on the results of the first experiment, two further experiments were set up, each with six groups. In total 299 four-week-old Lohman Brown female chickens were used for the experiments. The infection dose of $E$. coli was set to be $10^{8} \mathrm{cfu}$ in the two experiments, given as either an oral or a tracheal infection. In all experiments $A$. galli and E. coli were given either as single or combined infections. In the case of combined infections the chickens were inoculated with an interval of 7 days between the two infections. In the second experiment the animals were followed for 14 days after the second infection, whereas the animals in the third experiment were followed 4 weeks after the second infection. Group distributions and inoculation schemes are given in Tables 2 and 3.

\section{Parameters measured}

All chickens were weighed just as clinical signs were recorded. Furthermore, re-isolation and counting of the nalidixic-acid-resistant $E$. coli (Lee and Arp 1998) and A. galli larvae/adults (Permin and Hansen 1998) was carried out on all animals dying during the experiment and at the end of the experiment. Likewise, pathological lesions, if any, were recorded on all chickens.

\section{Statistical analyses}

All data were stored in the statistical programme GraphPad Prism (GraphPad Software Incorporated 2000). One-way analysis of variance (ANOVA), chi-square analysis ( $\boldsymbol{x}^{2}$-analysis) or Students t-test were used to analyse the data.

\section{Results}

Determination of dose and infection route of E. coli

Pathological lesions associated with an E. coli infection were seen in the group given $E$. coli by tracheal route with $10^{8} \mathrm{cfu}$ and in the groups infected with $A$. galli combined with a secondary E. coli infection given by tracheal route with a dose of $10^{4}$ or $10^{8} \mathrm{cfu}$. Pathological lesions were observed in four, three and two chickens respectively in these groups (Table 1). However, E. coli could only be re-isolated from three of these animals. One animal died in the group infected with $A$. galli and $E$. coli given by tracheal route with $10^{4} \mathrm{cfu}$ while two animals died in the group given only a tracheal oral dose of $10^{8} \mathrm{E}$. coli. These three animals all tested positive for E. coli. A chi-square analysis showed no significant difference in mortality rates between the groups ( $p>0.05$ ).

A. galli larvae were recovered from all four groups infected with the parasite. An analysis of variance showed that the worm burdens were not significantly different between groups ( $>0.05$ ).

The animals were weighed four times during the first experiment. The mean weight gains are given in Figure 1. One week after the first infection with either A. galli or E. coli differences were seen between the infected groups when compared to the control group $(p<0.05)$, but there was no significant difference between the infected groups. At slaughter (fourth weighing) an analysis of variance showed that the group infected with $A$. galli and subsequently with $E$. 
Table 1. Infection groups used for the determination of dose and infection route of $E$. coli

\begin{tabular}{|c|c|c|c|}
\hline Group & Type of infection & Group size & Pathological findings \\
\hline
\end{tabular}

$\mathrm{Ag}+\mathrm{Ec} 40 \quad$ A. galli (primary infection) given as oral

$\mathrm{Ag}+\mathrm{Ec} 4 \mathrm{~T} \quad$ A. galli (primary infection) given as oral

$\mathrm{Ag}+\mathrm{Ec} 8 \mathrm{O} \quad$ A. galli (primary infection) given as oral

$\mathrm{Ag}+\mathrm{Ec} 8 \mathrm{~T} \quad$ A. galli (primary infection) given as oral

Ec4O

Ec4T

$\mathrm{Ec} 8 \mathrm{O}$

Ec8T

Control dose of 500 embryonated eggs $+E$. coli (secondary infection) given as oral dose of $10^{4} \mathrm{cfu}$. dose of 500 embryonated eggs $+E$. coli (secondary infection) given as tracheal dose of $10^{4} \mathrm{cfu}$. dose of 500 embryonated eggs + E. coli (secondary infection) given as oral dose of $10^{8}$ cfu. 6 dose of 500 embryonated eggs $+E$. coli (secondary infection) given as tracheal dose of $10^{8} \mathrm{cfu}$.

5

6

6

E. coli given as oral dose of $10^{4} \mathrm{cfu}$.

E. coli given as tracheal dose of $10^{4} \mathrm{cfu}$.

E. coli given as oral dose of $10^{8} \mathrm{cfu}$.

E. coli given as tracheal dose of $10^{8} \mathrm{cfu}$.
No pathological findings

1 animal with polyserositis, $\dagger$ 1 animal with pericarditis and doublesided pneumonia

No pathological findings

1 animal with fibrinopurulent polyserositis

1 animal with pericarditis and purulent double sided pneumonia

1 animal with pericarditis and double sided airsacculitis

$5 \quad$ No pathological findings

6 No pathological findings

$6 \quad$ No pathological findings

62 animals with pericarditis and double sided airsacculitis 1 animal with polyserositis and right sided pneumonia, $\dagger$ 1 animal with polyserositis and double sided pneumonia, $\uparrow$ No pathological findings

$\dagger$ the animal died during the first week of the infection trial.

coli given as a tracheal infection with $10^{8}$ bacteria had a significantly lower $(\mathrm{p}<0.05)$ weight gain compared to all the other groups. But also the groups infected with $E$. coli given as an oral or tracheal infection with a dose of $10^{8}$ bacteria and the group given $A$. galli and subsequently
E. coli with $10^{4}$ bacteria had a significantly lower weight gain $(\mathrm{p}<0.05)$ at time of slaughter compared to the control group.

Based upon the overall results obtained in oneweek-old chickens, which are more susceptible to $E$. coli infections, $10^{8}$ E. coli was chosen as 
the dose of infection in both oral and tracheal infections and four-week-old chickens were used instead (Dho-Moulin and Fairbrother 1999).

\section{Final experiments}

In the second experiment $A$. galli was given as the primary infection followed by $E$. coli. The results of the second experiment are outlined in Table 2. Pathological lesions consistent with $E$. coli infections were seen in the group infected with $A$. galli followed by $E$. coli given as a tracheal dose of $10^{8} \mathrm{cfu}$. in addition to the two groups infected by oral or tracheal route with only E. coli. Pathological lesions were observed in four, one and four chickens in these groups, respectively. Pathological lesions were not seen in the group infected with only A. galli or in the groups infected with first $A$. galli and subsequently with $E$. coli given as an oral dose of $10^{8}$ cfu.

Mortality was encountered in the groups infected with $E$. coli given as an oral or tracheal infection and in the group with combined $A$. galli and tracheal E. coli infection. Mortality due to cannibalism was seen in the control group. A chi-square analysis for differences in mortality showed no significant differences be-

Table 2. Number of chickens, parasitic (A. galli), bacterial (nalidixic-acid-resistant O78 E. coli) and pathological findings of second experiment with primary $A$. galli infections superimposed by secondary $E$. coli infections.

\begin{tabular}{|c|c|c|c|c|c|c|}
\hline \multirow[t]{2}{*}{ Group } & \multirow{2}{*}{$\begin{array}{l}\text { Type, route and dose } \\
\text { of infection }\end{array}$} & \multirow[t]{2}{*}{ Group size } & \multirow{2}{*}{$\begin{array}{l}\text { No of dead } \\
\text { animals } \\
\text { during } \\
\text { experiment }\end{array}$} & \multicolumn{3}{|c|}{ Post-mortem findings at slaughter } \\
\hline & & & & $\begin{array}{l}\text { Pathological } \\
\text { changes }\end{array}$ & $\begin{array}{l}\text { Worm } \\
\text { burden } \\
\text { ( } \pm \text { S.D.) }\end{array}$ & $\begin{array}{l}\mathrm{Re}- \\
\text { isolation } \\
\text { of } E \text {. coll }\end{array}$ \\
\hline $\mathrm{Ag}$ & Oral $500 \mathrm{~A}$. galli eggs & 25 & 0 & 25 neg. & $\begin{array}{l}5.6 \pm 11 \\
0\end{array}$ & 25 neg. \\
\hline $\mathrm{Ag}+\mathrm{Ec} 8 \mathrm{O}$ & $\begin{array}{l}\text { Oral } 500 \mathrm{~A} \text {. galli } \mathrm{eggs}+\text { oral } \\
\text { E. coli with } 10^{8} \mathrm{cfu}\end{array}$ & 37 & 0 & 37 neg. & $\begin{array}{l}14.0 \pm 1 \\
8.0\end{array}$ & 37 neg. \\
\hline $\mathrm{Ag}+\mathrm{Ec} 8 \mathrm{~T}$ & $\begin{array}{l}\text { Oral } 500 \mathrm{~A} \text {. galli eggs }+ \\
\text { tracheal } E . \text { coli with } 10^{8} \mathrm{cfu}\end{array}$ & 38 & $1^{1}$ & $\begin{array}{l}1 \mathrm{PS}+\mathrm{PC}+ \\
\text { AS, } 1 \text { FPPS } \\
+\mathrm{LNC}, 1 \\
\text { FPPC, } 34 \\
\text { neg. }\end{array}$ & $\begin{array}{l}10.0 \pm 1 \\
4.0\end{array}$ & 37 neg. \\
\hline $\mathrm{Ec} 8 \mathrm{O}$ & Oral $E$. coli with $10^{8} \mathrm{cfu}$ & 25 & $1^{2}$ & 24 neg. & 0 & 24 neg. \\
\hline Ec8T & Tracheal E. coli with $10^{8}$ cfu & 25 & $4^{3}$ & 21 neg. & 0 & 21neg. \\
\hline Control & Uninfected control & 25 & $3^{4}$ & 22 neg. & 0 & 22 neg. \\
\hline
\end{tabular}

$\mathrm{AS}=$ airsacculitis; $\mathrm{FP}=$ fibrinopurulent $\mathrm{L}=$ =liver; neg=negative; $\mathrm{NC}=$ necrosis; $\mathrm{PC}=$ =pericarditis; $\mathrm{PS}=$ polyserositis; $\mathrm{SP}=\mathrm{spleen}$;

${ }^{1}$ One animal died after the 2 nd infection testing positive for a nalidixic-acid-resistant $E$. coli in liver and spleen and with necrosis of the spleen.

${ }^{2}$ One animal died after first infection with polyserositis, but was negative for bacteriology.

${ }^{3}$ Four animals died after the infection with $E$. coli; three animals tested positive for a nalidixic-acid-resistant $E$. coli in liver and spleen. Of these two animals had fibrinopurulent pericarditis, one had polyserositis and the remaining $E$. coli negative chicken had fibrinopurulent salpingitis.

${ }^{4}$ Three animals died due to cannibalism, but had no other pathological findings. 
Table 3. Number of animals, parasitic (A. galli), bacterial (nalidixic-acid-resistant O78 E. coli) and pathological findings of third experiment with primary $E$. coli infection superimposed by secondary A. galli infection

\begin{tabular}{|c|c|c|c|c|c|c|}
\hline \multirow[t]{2}{*}{ Group } & \multirow{2}{*}{$\begin{array}{l}\text { Type, route and dose } \\
\text { of infection }\end{array}$} & \multirow[t]{2}{*}{ Group size } & \multirow{2}{*}{$\begin{array}{l}\text { No of dead } \\
\text { animals } \\
\text { during } \\
\text { experiment }\end{array}$} & \multicolumn{3}{|c|}{ Post-mortem findings at slaughter } \\
\hline & & & & $\begin{array}{l}\text { Pathological } \\
\text { changes }\end{array}$ & $\begin{array}{l}\text { Worm } \\
\text { burden } \\
( \pm \text { S.D. })\end{array}$ & $\begin{array}{l}\text { Re- } \\
\text { isolation } \\
\text { of E. coli }\end{array}$ \\
\hline $\mathrm{Ag}$ & Oral 500 A. galli eggs & 20 & 0 & 20 neg. & $0.8 \pm 1.4$ & 20 neg. \\
\hline $\mathrm{Ec} 8 \mathrm{O}+\mathrm{Ag}$ & $\begin{array}{l}\text { Oral E. coli with } 10^{8} \mathrm{cfu}+\text { oral } \\
500 \text { A. galli eggs }\end{array}$ & 21 & 0 & 21 neg. & $0.3 \pm 0.5$ & $21 \mathrm{neg}$ \\
\hline $\mathrm{Ec} 8 \mathrm{~T}+\mathrm{Ag}$ & $\begin{array}{l}\text { Tracheal E. coli with } 10^{8} \mathrm{cfu}+ \\
\text { oral } 500 \text { A. galli eggs }\end{array}$ & 21 & $7^{1,4}$ & 14 neg. & $0.1 \pm 0.3$ & 14 neg. \\
\hline Ec8O & Oral E. coli with $10^{8} \mathrm{cfu}$ & 21 & 0 & 21 neg. & 0 & 21 neg. \\
\hline Ec8T & Tracheal E. coli with $10^{8} \mathrm{cfu}$ & 21 & $6^{2,4}$ & 15 neg. & 0 & 15 neg. \\
\hline Control & Uninfected control & 20 & 0 & 20 neg. & $0^{3}$ & 20 neg. \\
\hline
\end{tabular}

${ }^{1}$ Seven animals died after the second infection with $A$. galli. All were positive for a nalidixic_acid_resistant O78 E. coli and had extensive pathological changes, all with airsacculitis and fibrinopurulent pericarditis.

${ }^{2}$ Six animals died after the first infection with E. coli. All were positive for a nalidixic_acid_resistant O78 E. coli and five chickens had pathological with airsacculitis and fibrinopurulent pericarditis. One chicken had no pathological changes.

${ }^{3}$ Few larvae were recovered in the uninfected groups.

${ }^{4}$ Significantly more animals died compared to the remaining groups.

tween the groups ( $>0.05)$. Pure isolates of $E$. coli were obtained from liver and spleen from the group with combined $A$. galli and tracheal E. coli infection and in the group infected with only tracheal E. coli. At slaughter, A. galli larvae were isolated from the three groups initially infected with $A$. galli. A significantly lower worm burden was seen in the $A$. galli group compared to the combined groups $(\mathrm{p}<0.01)$. It was not possible to recover the nalidixic-acidresistant $\mathrm{O} 78$ stain used for inoculation of the birds at time of slaughter.

The mean weight gains for all groups are given in Figure 2. After the first infection with $A$. galli until the second infection a slight weight depression was seen in all groups including the control group. An analysis of variance between all groups at time of the first and second infec- tion showed no significant difference between the groups ( $p>0.05)$. However, after the second infection (and for the remaining time of the experiment), with $E$. coli given as a tracheal or oral infection, a significantly lower weight gain was seen in these groups compared to all other groups $(\mathrm{p}<0.05)$.

In the third experiment $E$. coli was given as the primary infection followed by $A$.galli. The results of the third experiment are outlined in Table 3. Pathological changes due to E. coli were only found in the two groups given $E$. coli by tracheal route, one of which was additionally infected with $A$. galli. In this group seven animals died after the secondary infection with $A$. galli, while only six chickens died in the group infected tracheally with E. coli. All were positive for $E$. coli and had extensive pathological 
changes corresponding to $E$. coli infections. A $\boldsymbol{x}^{2}$-analysis showed that a significantly higher number of animals died in these two groups compared to the others $(\mathrm{p}=0.056)$.

At slaughter larvae were recovered from all groups infected with $A$. galli. A t-test revealed that there were significantly lower worm burdens in the combined infection groups compared to the group only infected with $A$. galli $(\mathrm{p}<0.05)$. The nalidixic-acid-resistant $\mathrm{O} 78$ strain used for inoculation of the birds was not recovered at the time of slaughter.

The mean weight gains are given in Figure 3. A weight depression was seen for the two groups infected with $E$. coli given as a tracheal primary infection. Additional weight loss was observed for the group infected additionally with $A$. galli. An analysis of variance between all groups at the time of the first infection showed no significant difference in weight gain between the groups ( $>0.05)$. However, after the infection with $E$. coli there was a significant difference between the groups infected first with $E$. coli by tracheal route and the group infected secondly with A. galli $(\mathrm{p}<0.05)$ compared to the other groups. The weight gain for the group infected with only with $E$. coli by tracheal route was significantly lower $(\mathrm{p}<0.05)$ two weeks after infection. At the time of slaughter there was a significant difference between the group tracheally infected with $E$. coli followed by $A$. galli compared to the other groups $(\mathrm{p}<0.05)$ whereas the
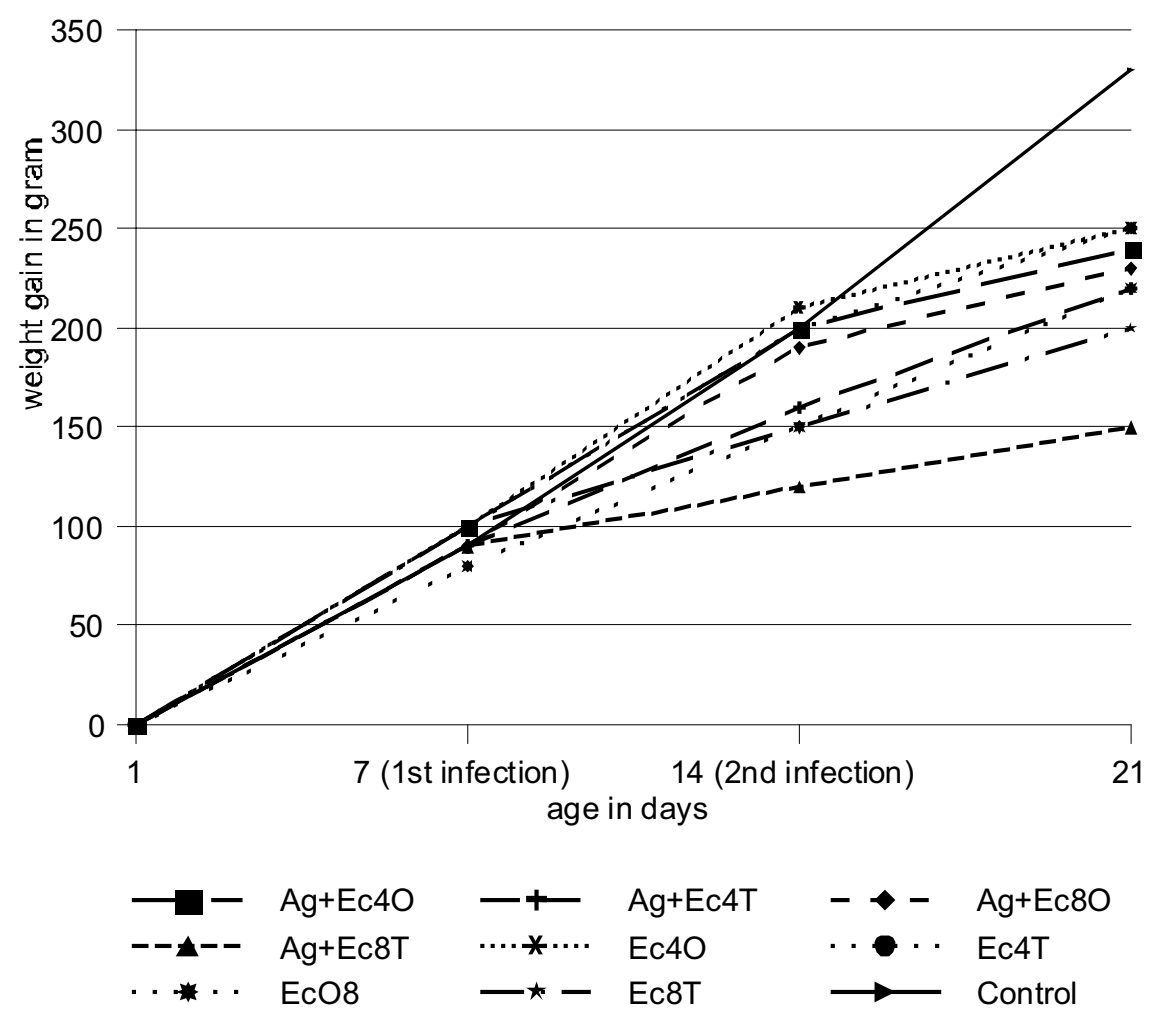

Figure 1. Average weight gain of the 9 groups in experiment 1 (determination of dose and infection route of E. coli) where $\mathrm{Ag}=A$. galli, $\mathrm{Ec}=E$. coli, $\mathrm{O}=$ oral, $\mathrm{T}=$ tracheal, $4=10^{4} \mathrm{cfu}$ and $8=10^{8} \mathrm{cfu}$. 
single infected $E$. coli group had a weight gain similar to the other groups ( $>0.05)$.

\section{Discussion}

In total, three experiments were carried out to examine the effect of various combinations of $A$. galli and E. coli infections in growing chickens of layer type. Characteristic pathological lesions due to E. coli were seen in all the groups tracheally infected with $E$. coli as previously described by Dho-Moulin and Fairbrother (1999) and Nakamura et al. (1985), while lesions were absent in those inoculated orally. Pathological lesions were not observed in relation to the $A$. galli infection. This is presumably due to the rather low worm burdens observed in the chickens (Ikeme 1971, Permin et al. 1997a). The combined infections of E. coli and A. galli did not produce more pathological lesions, which is unexpected as simultaneous parasitic infections often create more severe pathological lesions (Christensen et al. 1987). However, a trend for increased mortality rates was seen in the groups infected with the two pathogens, but it was not confirmed statistically.

Significantly different worm burdens were isolated from the intestinal tract of the $A$. galli and E. coli infected groups compared to the $A$. galli infected groups. With $A$. galli given first followed by an oral or a tracheal E. coli infection, significantly higher worm burdens were observed in both groups. Johnson and Reid (1973)
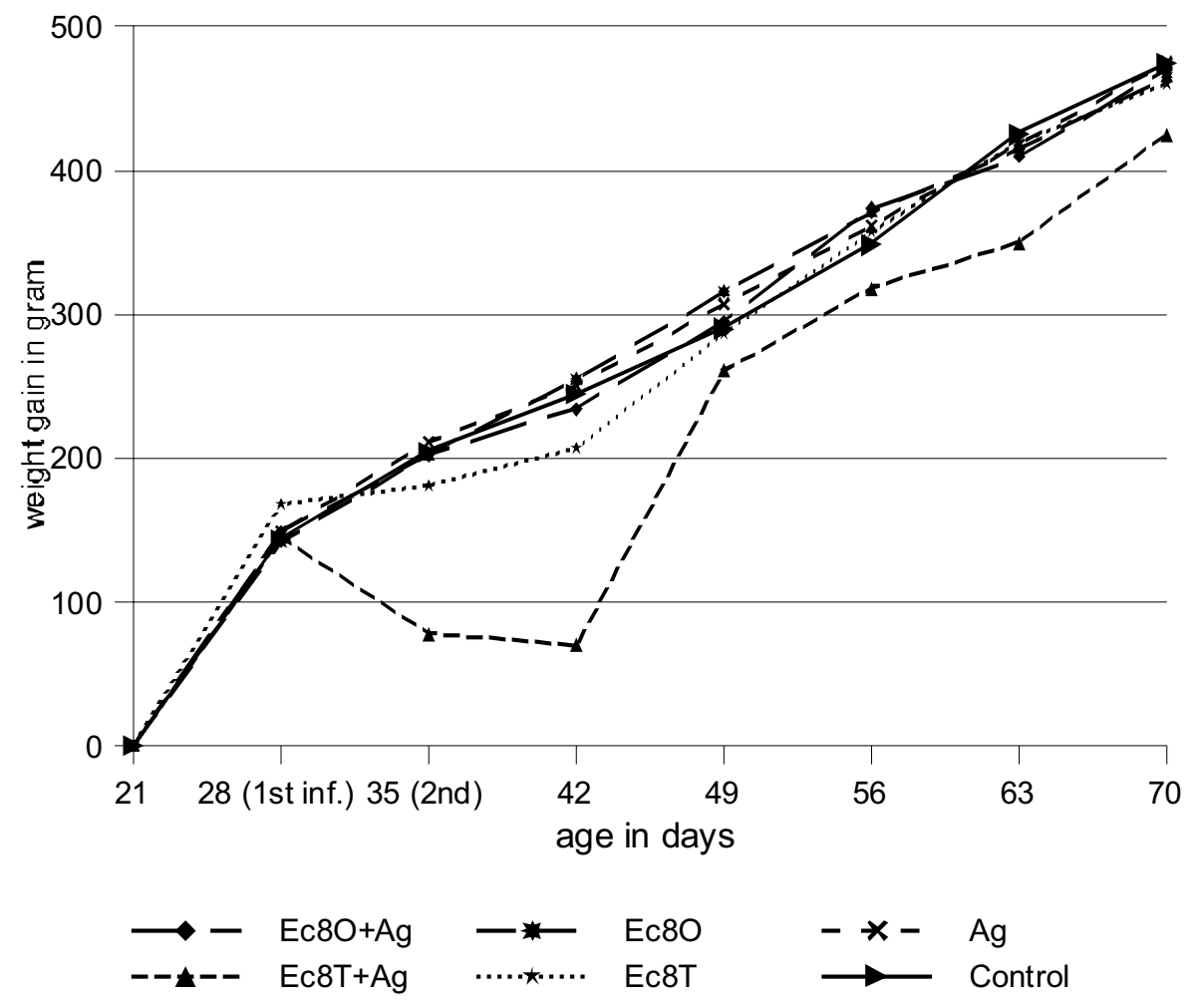

Figure 2. Weight gain in final (2nd experiment) where $A$. galli was given as the primary infection and $E$. coli was given as the second infection and where $\mathrm{Ag}=A$. galli, $\mathrm{Ec}=E$. coli, $\mathrm{O}=$ oral, $\mathrm{T}=$ tracheal and $8=10^{8} \mathrm{cfu}$. 
had similar results on the establishment of $A$. galli when chickens were infected with Bacillus subtilis and B. cereus. With a tracheal or oral $E$. coli infection given first followed by an $\mathrm{A}$. galli infection the opposite situation was observed. Other studies have shown, that in antibioticsterilized chickens, the presence of $B$. mesentericus, B. megatherium and Lactobacillus acidophilus in the intestine inhibited the establishment of A. galli (Stefanski and Przyja kowski 1967) whereas Okulewicz and Zlotorzycka (1985) showed that A. galli inhibited the natural bacterial micro flora of the intestine of hens. The mechanisms for these phenomena are not known, but possibly related to the development of immunity. A recent paper by Pritchard and Brown (2001) has indicated that although cellular response mechanisms of bacteria and parasites are related to each their pathway (Th2 for parasites and Th1 for bacteria) there is a balance between the two pathways. Thus a parasite infection might favour the Th2 cell development and indirectly suppress the establishment of bacteria, or vice-versa.

Furthermore, lower worm burdens were detected in the third experiment which ran for additional weeks. Similar observations were made by Tongson and McCraw (1967) where a nonspecific age related immunity developed in growing chickens around the age of 3 months. The mechanism could be a self-cure mechanism as recently described in chickens in rela-
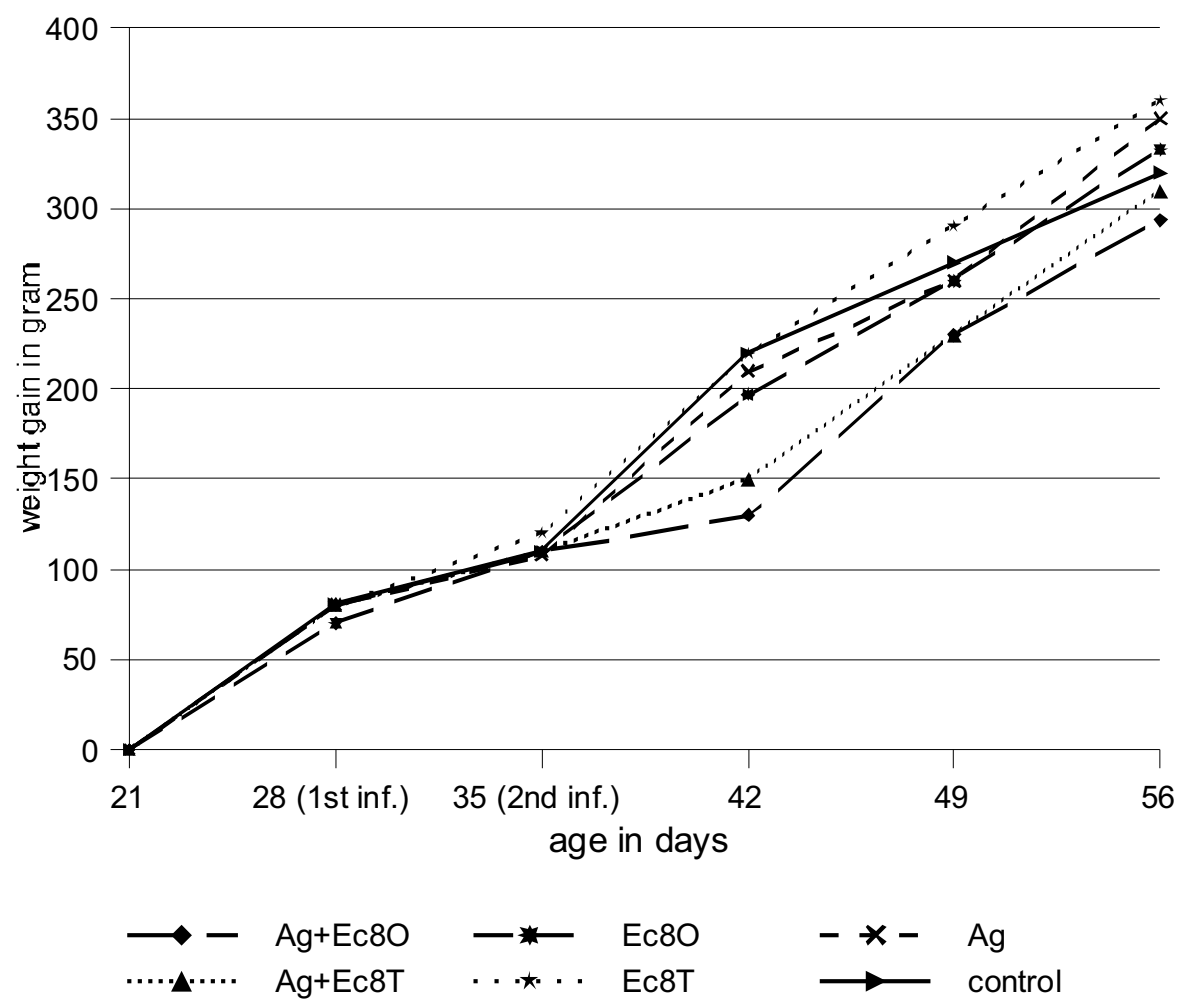

Figure 3. Weight gain in final experiment (3rd experiment) where E. coli was given as the primary infection and A. galli was given as the second infection and where $\mathrm{Ag}=A$. galli, Ec $=E$. coli, $\mathrm{O}=\mathrm{oral}, \mathrm{T}=$ tracheal and $8=10^{8} \mathrm{cfu}$. 
tion to A. galli (Permin and Ranvig 2001). Balic et al. (2000) discussed the expulsion of trichostrongyle nematodes after primary infections in rodents speculating that the mechanism behind is genetically related as also described by Behnke et al. (1992). The expulsion is mainly seen in rodents and not in larger animals (Balic et al. 2000).

The nalidixic-acid-resistant $E$. coli strain was only isolated from the chickens which died during the experiment and not from any of the animals at slaughter. Similar findings have been reported by Leitner and Heller (1992), who could not isolate an orally inoculated nalidixic-acidresistant 078 from the trachea or from the blood in stressed turkeys. However, in orally infected broiler chickens, stress resulted in bacteremia and mortality.

In the experiments significantly lower weight gains were seen in the groups given $E$. coli as a tracheal infection. Weight depression as a result of tracheal $E$. coli infections is in accordance with the findings of other researchers (DhoMoulin and Fairbrother 1999). It was further shown that the combined infection with $A$. galli had a significant added negative impact on weight gain. Interestingly a primary infection with $A$. galli followed by an oral infection with E. coli also had a significantly negative impact on the weight gain.

Young birds (4-8 weeks) may have a brief period of anorexia and depression after infection with $E$. coli followed by acute septicaemia with mortality. However, weight depression was also seen after an oral $E$. coli infection when $A$. galli eggs were given as the primary infection. This may be related to damage of the intestinal mucosa leading to loss of blood and, probably, establishment of a secondary infection such as $E$. coli (Herd and McNaught 1975). Likewise, infections with $A$. galli have been reported to cause reductions in the growth rate, weight loss and mortality in broilers (Ackert and Herrick
1928, Reid and Carmon 1958, Ikeme 1971, He et al. 1990). The severity of the intestinal lesions may depend on the number of worms established in the intestine (Ikeme 1971). However, in this study only moderate weight losses were seen due to the parasite and only in the very young birds (1-3 weeks) whereas the older birds apparently were able to compensate for the infection. This is in contrast to earlier findings (Ackert and Herrick 1928, Reid and Carmon 1958). Permin and coworkers (unpublished) have observed similar findings in growing chickens where the animals apparently compensated for the loss due to the parasites by an increased feed intake.

The findings of this study indicate a negative relationship between concurrent infections of $E$. coli and $A$. galli. The mechanisms behind the observed relationship are not known, but might be related to immune mechanisms (Pritchard and Brown 2001). Leitner and Heller (1992) investigated the potential of pathogenic E. coli to penetrate the bloodstream via the intestinal mucosa in normal and stressed turkeys and chickens, but did not examine this in relation to stress caused by parasites. Their studies showed that, in orally infected turkeys, the pathogenic bacteria (a nalidixic-acid-resistant O78) remained in the intestine where it replaced $10 \%$ to $50 \%$ of the native coliform flora. But in orally infected broiler chickens, stress resulted in bacteremia and mortality. In our study significant weight depressions were seen in the orally infected chickens, which indicates that $A$. galli, when given as a primary infection, has an damaging effect on the intestinal mucosa (Herd and McNaught 1975) enabling $E$. coli to establish when it is given as an oral infection. However, an increased mortality was not seen. An additional effect of $A$. galli was seen in the group secondarily infected with $A$. galli. This could be related to an immunosuppressive effect of A. galli (Malviya et al. 1988, Sharma 1997, Roepstorff et al. 1999). 


\section{Conclusion}

In conclusion combined infections of $A$. galli and $E$. coli can have a significant impact on confined and free-range chickens keeping in mind that both infections are common in such production systems. Further studies are needed in order to determine the underlying mechanisms of combined infections of $A$. galli and $E$. coli in growing and adult chickens.

\section{Acknowledgements}

We would like to thank Margrethe Pearman, Rikke Frahm Lundvig, Pernille Ginsbo, Pia Mortensen, Stina Holm, Niels Midtgaard, Jørgen Olesen, Johnny Jensen, Thomas Bernau Kristensen and Rene Bülow for technical assistance during the experiments. Financial support by the Council for Development Research (Danida) through the project "Multiple infections in free-range poultry" is highly appreciated. All experiments complied with current regulations for the use of experimental animals in Denmark.

\section{References}

Ackert JE: The morphology and life history of the fowl nematode Ascaridia lineata (Schneider). Parasitol. 1931, 23, 360-379.

Ackert JE, Herrick CA: Effects of the nematode Ascaridia lineata (Schneider) on growing chickens. J. Parasitol. 1928, 15, 1-15.

Balic A, Bowles VM, Meeusen EN: Cellular profiles in the abomasal mucosa and lymph node during primary infection with Haemonchus contortus in sheep. Vet. Imm. Immunopathol. 2000, 75, 109120.

Baron RR, Hansen MF, Lord TH: Bacterial flora of the roundworm Ascaridia galli (Schrank) and its relationship to the host flora. Exp. Parasitol. 1960, 9, 281-292.

Behnke JM, Barnard CJ, Wakelin D: Understanding chronic nematode infections: evolutionary considerations, current hypotheses and the way forward. Int. J. Parasitol. 1992, 22, 861-907.

Chadfield MS, Permin A, Nansen P, Bisgaard M: Investigation of the parasitic nematode Ascaridia galli as a potential vector for Salmonella dissemination in broiler poultry. Parasitol. Res. 2001, 87, 317-325.

Christensen N, Nansen P, Fagbemi BO, Monrad J: Heterologous antagonistic and synergistic interactions between helminths and between helminths and protozoans in concurrent experimental infections of mammalian hosts. Parasitol. Res. 1987, 73, 387-410.

Dho-Moulin M, Fairbrother JM: Avian pathogenic Escherichia coli (APEC). Vet. Res. 1999, 30, 299-316.

Gross WB: Factors affecting the development of respiratory disease complex in chickens. Avian Dis. 1990, 34, 607-610.

He S, Susilowati VEHS, Purwati E, Tiuria R: An estimate of meat production loss in native chicken in Bogor and its surrounding district due to gastrointestinal helminthiasis. Proceedings of the 5th National Congress of Parasitology. East Java, Indonesia, 1990, $57 \mathrm{p}$.

Herd RP, McNaught DJ: Arrested development and the histotropic phase of Ascaridia galli in the chicken. Int. J. Parasitol. 1975, 5, 401-406.

Ikeme MM: Observations on the pathogenicity and pathology of Ascaridia galli. Parasitol. 1971, 63, 169-179.

Johnson J, Reid WM: Ascaridia galli (nematoda): Development and survival in gnotobiotic chickens. Exp. Parasitol. 1973, 33, 95-99.

Lee MD, Arp LH: Colibacillosis. In Swayne, D.E., Glisson, J.R., Jackwood, M.W., Pearson, J.E. and Reed, W.M. (Eds.), A Laboratory Manual for the Isolation and Identification of Avian Pathogens 4th edn. The American Association of Avian Pathologists, 1998, pp. 14-16.

Leitner G, Heller ED: Colonization of Escherichia coli in young turkeys and chickens. Avian Dis. 1992, 36, 211-220.

Malviya MC, Dwivedi P, Varma TK: Effect of irradiated Ascaridia galli eggs on growth and cell-mediated immune responses in chickens. Vet. Parasitol. 1988, 28, 137-141.

Nakamura K, Maecla M, Imada Y, Imada T: Pathology of spontaneous colibacillosis in a broiler flock. Vet. Pathol. 1985, 22, 592-597.

Okulewicz A, Zlotorzycka J: Connections between Ascaridia galli and the bacterial flora in the intestine of hens. Ang. Parasitol. 1985, 26, 151-155.

Permin A, Bojesen M, Nansen P, Bisgaard M, Frandsen F, Pearman M: Ascaridia galli populations in chickens following single infections with different dose levels. Parasitol. Res. 1997a, 83, 614617.

Permin A, Pearman M, Nansen P, Bisgaard M, Frandsen $F$ : An investigation on different media for embryonation of Ascaridia galli eggs. Helminthologia 1997b, 34, 75-79. 
Permin A, Hansen JW: Epidemiology, diagnosis and control of poultry parasites. Rome, Italy: Food and Agriculture Organisation, 1998, pp. 74-105, 111-118.

Permin A, Nansen P, Bisgaard M, Frandsen F: Investigations on the infection and transmission of $A s-$ caridia galli in free range chickens kept at different stocking rates. Avian Pathol. 1998, 27 (4), 382-389.

Permin A, Bisgaard M, Frandsen F, Pearman M, Kold $J$, Nansen P: The prevalence of gastrointestinal helminths in different poultry production systems. Brit. Poult. Sci. 1999, 40, 439-443.

Permin A, Ranvig H: Genetic resistance in relation to Ascaridia galli in chickens. Vet. Parasitol. 2001, 102(1-2), 101-111.

Pritchard DI, Brown A: Is Necator americanus approaching a mutualistic symbiotic relationship with humans? Trends in Parasitol. 2001, 17, 169172.

Reid WM, Carmon JL: Effects of numbers of Ascaridia galli in depressing weight gains in chickens. Trop. Ani. Health Prod. 1958, 44, 183-186.

Roepstorff A, Nørgaard-Nielsen G, Permin A, Simonsen $H B$ : Male behaviour and male hormones in Ascaridia galli infected hens. Proceedings of the 17th International Conference of the World Association for the Advancement of Veterinary Para- sitology, Copenhagen, Denmark, 1999, p d5.02.

Sharma JM: The structure and function of the avian immune system. Acta Vet. Hun. 1997, 45, 229238.

Stefanski W, Przyjakowski Z: Nouvelles recherches sur l'influence de la flora bactérienne sur l'établissement des helminthes dans leurs hôtes. Acta Parasitol. Pol. 1967, 15, 285-287.

Tongson MS, McCraw BM: Experimental ascaridiasis: Influence of chicken age and infective egg dose on structure of Ascaridia galli populations. Exp. Parasitol. 1967, 21, 160-172.

Thrusfield M: Veterinary Epidemiology (2nd edn). Oxford: Blackwell Science, 1995.

Vidotto M, Moeller EE, de Freitas JC, Alfieri AA, Guimares $I G$, Santos DS: Virulence factors of avian Escherichia coli. Avian Dis. 1990, 34, 531538.

White DG, Dho-Moulin M, Wilson RA, Whittam TS: Clonal relationships and variation in virulence among Escherichia coli strains of avian origin. Micro. Pathogen. 1993, 14, 399-409.

(Received 2005; accepted January 2, 2006).

Reprints may be obtained from: A. Permin, Danish Toxicology Centre, Kogle Allé 2, DK-2970 Hørsholm, Denmark. * Corresponding author. Tel: +45 45652370. Fax: +45 45762455. E-mail: ape@dtc.dk (A. Permin). 